$11-1-2011$

\title{
Aspects of Fatigue Failure Mechanisms in Polymer Fuel Cell Membranes
}

\author{
Ahmet Kusoglu \\ University of Delaware \\ Michael H. Santare \\ University of Delaware
}

Anette M. Karlsson

Cleveland State University, a.karlsson@csuohio.edu

Follow this and additional works at: https://engagedscholarship.csuohio.edu/enme_facpub

Part of the Mechanical Engineering Commons

How does access to this work benefit you? Let us know!

\section{Publisher's Statement}

This is the accepted version of the following article: Kusoglu, A., Santare, M. H., and Karlsson, A. M., 2011, "Aspects of Fatigue Failure Mechanisms in Polymer Fuel Cell Membranes," Journal of Polymer Science Part B: Polymer Physics, 49(21) pp. 1506-1517., which has been published in final form at http://onlinelibrary.wiley.com/doi/10.1002/polb.22336/abstract

\section{Original Citation}

Kusoglu, A., Santare, M. H., and Karlsson, A. M., 2011, "Aspects of Fatigue Failure Mechanisms in Polymer Fuel Cell Membranes," Journal of Polymer Science Part B: Polymer Physics, 49(21) pp. 1506-1517.

This Article is brought to you for free and open access by the Mechanical Engineering Department at EngagedScholarship@CSU. It has been accepted for inclusion in Mechanical Engineering Faculty Publications by an authorized administrator of EngagedScholarship@CSU. For more information, please contact library.es@csuohio.edu. 


\title{
Aspects of Fatigue Failure Mechanisms in Polymer Fuel Cell Membranes
}

\author{
Ahmet Kusoglu, ${ }^{*}$ Michael H. Santare, Anette M. Karlsson \\ Department of Mechanical Engineering, University of Delaware, Newark, Delaware 19716 \\ Correspondence to: A. M. Karlsson (E-mail: karlsson@udel.edu)
}

INTRODUCTION Polymer electrolyte membrane (PEM) fuel cells have the potential to replace conventional fossil fuel-dependent combustion engines with clean and more efficient electric power sources. However, premature failure of the cell components, due to the aggressive environmental cell operating conditions, imposes a crucial technical barrier to the widespread commercialization of PEM fuel cells. ${ }^{1-3}$ These technical barriers must be overcome to provide durable and reliable fuel cell operation and to eventually make fuel cells a viable alternative to internal combustion engines. ${ }^{1-3}$ There are a multitude of issues to address pertaining to durability of fuel cells, and this work will focus on durability issues associated with the polymer membrane only. In particular, we aim to develop a foundation for life-prediction models, by linking experimental and numerical results to materials mechanics.

A common test to investigate the mechanical durability of PEMs is the relative humidity $(\mathrm{RH})$ cycle test. ${ }^{1,3-7}$ In this test, the cell is exposed to inlet gases that alternate rapidly between low and high relative humidities. During high humidity, the hydrated membranes swell, resulting in compressive membrane stresses, $\sigma^{\max R H}<0 . .^{8-10}$ If the compressive stresses supersede the elastic range, in-elastic deformations (either viscous or plastic) develop. In these cases, shrinkage of the compressively deformed membrane after dehydration leads to residual tensile stresses in the membrane, $\sigma^{\min \mathrm{RH}}=$
$\sigma^{\mathrm{R}}(>0)$. Thus, under cycles with high-enough changes in $\mathrm{RH}$, the membrane is subjected to alternating compressive and tensile stresses. Assembly conditions of the cell could also cause tensile stresses in the membrane due, for example, to a decrease in the humidity after assembly or deformation of the cell components. ${ }^{11}$ However, in such cases, the mean stress is shifted to a higher level, which may lead to cycling between "high" and "low" tensile stress, which would be a more severe case than is considered in this investigation. Consequently, a mechanical fatigue loading, $\Delta \sigma$, is induced since a cyclical change in the stress, $\Delta \sigma=\sigma^{\mathrm{min} \mathrm{RH}}$ $-\sigma^{\max R H}$, is caused by the change in the water content of the membrane, that is, $\Delta \lambda=\lambda^{\max R H}-\lambda^{\min R H}$, during $\mathrm{RH}$ cycling.

The mechanical fatigue loading and the associated stresses are responsible for one particular set of membrane failure mechanisms. Further evidence for this is provided by the observation that the low in-plane swelling strains of the reinforced GORE-SELECT ${ }^{B}$ membranes (GORE-SELECT and GORE and designs are trademarks of W. L. Gore \& Associates) have been shown to improve the lifetime compared to unreinforced membranes., ${ }^{42-15}$ Residual, in-plane tensile stresses in the membrane, $\sigma_{x}^{R}$, may explain the occurrence of the cracks in the membrane under cyclic loading. ${ }^{16}$ Similarly, the observed mechanical failures in the form of tearing, cracking, crazing, and delamination at the membrane/catalyst interface

*Present address: Lawrence Berkeley National Laboratory, 1 Cyclotron Road, MS70-108B, Berkeley, CA 94720. 
during these cyclic tests can be associated with the swellinginduced mechanical stresses. ${ }^{6,7,10,17,18}$ Another failure type is blistering, caused by the growth of voids associated with contaminant particles. ${ }^{19}$ These voids are initially filled with water and expand at higher temperatures due to the increasing vapor partial pressure and then coalesce to from larger voids. ${ }^{19}$ In addition to the repetitive swelling-shrinkage, the mismatch in the material properties and dimensional changes, and the effects of cycling below freezing temperatures (e.g., freeze/thaw cycles) can contribute to the mechanical failures in fuel cell operation. ${ }^{10,20,21}$

In fuel cell membrane electrode assemblies (MEAs), the failure location was found to be dependent on the cell configuration and operating conditions but independent of the MEA type and thickness. ${ }^{19}$ Failure in the forms of pinholes, cracks, and delamination is generally localized along low compression areas such as under the flow channels, 7,19,21 and tensile stresses that develop in the MEA upon shrinkage at ambient conditions are thought to be responsible for the crack formation observed in the MEAs. ${ }^{19}$ Formation of cracks during humidity cycling was observed both in situ and ex situ (in actual fuel cell operation and in experimental testing), and the density of cracks was found to increase with increasing $\mathrm{RH}$ amplitude. ${ }^{4,6,17,22}$ A similar trend was also observed in an ex situ fatigue test where the density of cracks was found to increase with an increase in the applied tensile stress. ${ }^{17}$ Cracks at the fractured surface can propagate through the membrane eventually resulting in gas leakage or crossover. ${ }^{3,7,23}$ In addition, the mechanical properties were also found to degrade when the membranes degrade chemically either during the fuel cell operation $^{24,25}$ or ex situ (in the absence of any mechanical loads). ${ }^{17,26,27}$ Lastly, even though chemical degradation is primarily responsible for the decomposition of the membrane and material losses, the stresses contribute to the failure mechanisms by propagating cracks or by forming crazes, and therefore opening new surfaces for degradation. For example, a recent study reported, using a gas-phase ex situ chemical degradation test, that the degradation rate increased when the membrane was under tension providing evidence for combined chemical-mechanical effects. ${ }^{28}$ Thus, we believe that chemical degradation and mechanical failure are related at a fundamental level.

Numerical simulations of swelling-induced fatigue stresses in fuel cell membranes during $\mathrm{RH}$ cycling ${ }^{9}$ will be used in this work to develop a qualitative modeling frame for future lifeprediction models, utilizing likely failure criterion in polymers. Based on the comparison between the numerical experiments presented here and actual fuel cell test data from Lai et al., ${ }^{7}$ we will discuss the possible failure mechanisms in ionomer membranes.

The aim of this article is to investigate the qualitative behavior of PEMs using possible failure criteria in polymers and to discuss how suitable they are for analyzing the damage mechanisms in polymer fuel cell membranes. A quantitative life prediction model is beyond the scope of this article.

\section{FAILURE MECHANISMS IN IONOMER MEMBRANES}

\section{Background}

To our knowledge, only a limited number of studies are available in the open literature discussing the fatigue behavior of ionomer membranes. In the work of Hara et al. ${ }^{29,30}$ and Bellinger et al., ${ }^{31}$ the fatigue performance of polystyrene ionomers was reported to improve with increasing ion content. They attributed this to the filler effect of ionic aggregates in the polymer matrix acting as crosslinks, which suppresses crazing in favor of shear deformation. ${ }^{29-31}$ If this observation holds for other sulfonated ionomers, it follows that an ionomer cycled at high humidities could undergo less crazing since the higher humidity corresponds to higher "filler content." Even though durability of polymer membranes in fuel cell applications have received significant attention, 4,6,7,12,19,32 there is no in-depth investigation of crack formation and/or propagation based on any specific failure criteria. Ex situ characterization of the fracture behavior of PFSA membranes has been reported in a series of publications by Dillard and coworkers. ${ }^{22,33,34}$ For example, in a recent study by $\mathrm{Li}$ et al., $^{23}$ the ex situ fatigue response of polymer fuel cell membranes under biaxial loading was investigated using pressure-loaded blisters. They obtained typical fatigue lifetime curves that consist of a crack formation-dominated zone at high stress levels and a crack propagation-dominated zone at low stress levels. In the crack formation-dominated zone, cyclic stresses have been found to decrease faster than in the propagation-dominated zone, which is attributed to the crack/craze formation. ${ }^{23}$ Tang et al. ${ }^{17}$ also studied the ex situ fatigue behavior of PFSA membranes by conducting a cyclic tensile stress test. Crossover of gasses was found to increase with increasing $\mathrm{RH}$ amplitude, which can be attributed to the larger swellingshrinkage stresses. ${ }^{17}$

These ex situ stress cycling tests showed that fatigue failure occurs due to the propagation of cracks with craze formation through the material, even in the absence of electrochemical and geometric effects. However, the in situ effects (e.g., chemical degradation during cell operation and local imperfections) could further accelerate the failure by degrading the intrinsic properties, forming pinholes and opening new surfaces at the membrane/catalyst interface. Local flaws introduce stress concentrations, potentially triggering craze formation or crack propagation ultimately leading to catastrophic failure.

A number of studies have focused on the effect of expanded PTFE (ePTFE) reinforcement on the mechanical behavior and fatigue performance of ionomer membranes in fuel cells. ${ }^{4,12,15}$ For example, Liu et al. ${ }^{12}$ investigated the lifetime of various fuel cell membranes by measuring the $\mathrm{H}_{2}$ crossover rate and found that mechanical reinforcement with ePTFE provides an effective blunting mechanism that helps to slow the propagation of cracks. Li et al. ${ }^{23}$ also found that the reinforcement phase could delay the formation of cracks/crazes during pressure-loaded fatigue tests. Moreover, 
Patankar et al. $^{22}$ experimentally investigated the fracture energy of PFSA membranes and observed that the dominant failure mechanism in reinforced membranes is crack propagation in the ionomer phase rather than in the reinforcement layer. These observations are in agreement with the studies on the effect of fibrillation on preventing craze formation in PTFE, which forms the backbone of PFSA membranes, as will be discussed later. Reinforcement of fuel cell polymer membranes does not eliminate the failure completely; however, it increases the lifetime. For instance, in-plane cracks in the reinforced membranes can also be observed during accelerated RH cycle tests ${ }^{4}$ (Fig. 1).

\section{Fracture Energy (Toughness)}

Patankar et al. $^{22}$ and $\mathrm{Li}$ et al. $^{35}$ studied the critical strain energy release rate, $G_{c}$, or fracture energy of commercial PFSA membranes using a "knife-slit test." They conducted the test at various cutting speeds and angles to minimize the fracture energy during cutting so as to determine the intrinsic fracture energy of material. Their findings suggest that the fracture energy of Nafion ${ }^{\circledR}$ (Nafion ${ }^{\circledR}$ is a registered trademark of E.I. DuPont De Nemours \& Co. Nafion ${ }^{\circledR}$ membrane is a commercially available PFSA-based membrane commonly used in fuel cell applications.) membrane decreases with increasing humidity and/or temperature. However, the temperature effect on the fracture energy is larger than the humidity effect, ${ }^{22}$ and the effect of humidity on the fracture toughness almost vanishes in the highest temperature range investigated.

Nevertheless, the humidity dependence of fracture energy is important since the membrane's water content continually changes during a typical cell operation. Unfortunately, understanding of the effect of the humidity (i.e., the presence of water in the polymer) on failure mechanisms in ionomers is far from complete. In an early article on the effect of organic solvent on the crazing strain of polystyrene, ${ }^{36}$ the critical strain for crazing is found to be poorly correlated with the solubility of the crazing fluid. The authors used this finding to conclude the absence of a surface energy effect resulting in the fact that liquids do not decrease the crazing resistance, even though they decrease the flow stress. Therefore,

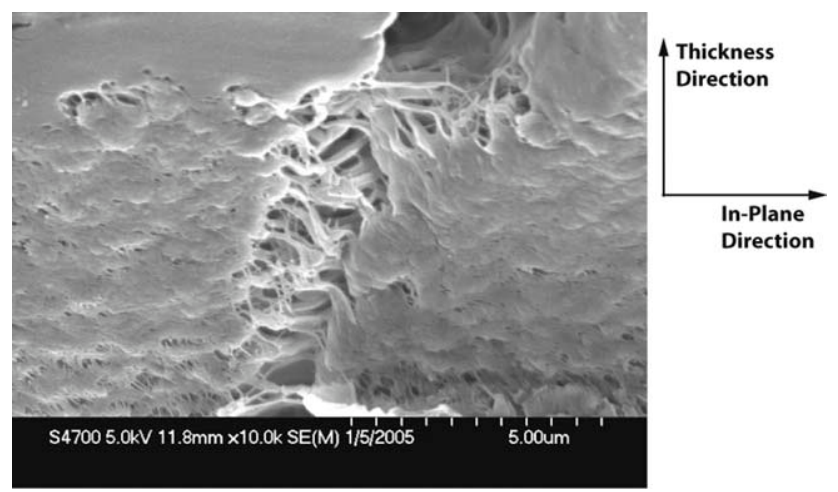

FIGURE 1 SEM image of a failed reinforced PFSA membrane after nitrogen $\mathrm{RH}$ cycling at $80{ }^{\circ} \mathrm{C}$ (See Crum and $\mathrm{Liu}^{4}$ for details. Image courtesy of M. Crum, WL Gore \& Associates). the effects of liquids on crazing plasticity and shear plasticity are different in nature. This can easily be confirmed by comparing the humidity effect on yield strength (controlling the plasticity) and fracture energy (controlling the rupture): From $0 \%$ to $90 \% \mathrm{RH}$ at elevated temperatures $\left(80-85{ }^{\circ} \mathrm{C}\right)$, the fracture energy for Nafion ${ }^{\circledR}$ membrane decreases by $15-20 \%,{ }^{22}$ while the yield strength decreases by more than $60 \%{ }^{37}$

Interestingly, when the membrane is in liquid water as compared to a 90-95\% RH environment, the fracture energy of the membrane decreases significantly such that a smooth humid-to-wet transition of the data and the corresponding hygrothermal master curve could not be obtained in the work presented by Patankar et al. $^{22}$ This rapid transition in the fracture energy of the membrane upon immersion in water is consistent with earlier observations on the stressstrain behavior of PFSA membranes. ${ }^{38,39}$ The membrane's deformation behavior in humid air was found to exhibit characteristic features of semicrystalline polymers with distinctive features such as the onset of plasticity, ${ }^{38,39}$ whereas in liquid water, an elastomeric stress-strain response with very low yield strength is observed. ${ }^{38}$ When the environment changes from saturated air to liquid water, almost a twofold increase is observed in the water content in the membrane. Higher swelling, combined with the possibility of morphological changes in water, ${ }^{40-42}$ might alter the structure of the membrane to such an extent that an entirely different hypothesis is needed to understand the origins of the changes in properties during vapor-to-liquid transition.

In addition, higher fracture energy for the reinforced PFSA membrane was reported indicating that the ePTFE reinforcement plays an important role in preventing the crack advance. $^{22}$ This increase in fracture energy could be attributed, for example, to strength of the ePTFE fibrils (Fig. 1) within the crack tip craze. ${ }^{43}$

The next section will briefly explore some common polymer failure criteria and their applicability to the study of fatigue behavior in polymer fuel cell membranes.

\section{Linear Elastic Fracture Mechanics}

Failure mechanisms involving crack initiation and propagation are commonly investigated using linear elastic fracture mechanics (LEFM). According to LEFM, a crack will propagate when the strain energy release rate during deformation supersedes the critical strain energy release rate. ${ }^{44,45}$ However, LEFM holds only for small scale yielding, that is, when the size of the plastic zone at the crack tip is small relative to the crack length and other geometric parameters such as the thickness of the polymer film [Fig. 2(A)]. Thus, to check the applicability of LEFM for thin polymer fuel cell membranes, the size of the plastic zone, $r_{\mathrm{p}}$ (defined in Fig. 2), for a crack propagating through the thickness of the membrane must be established. The size of the plastic zone can be correlated to refs. ${ }^{44}$ and ${ }^{45}$ :

$$
r_{\mathrm{p}} \propto\left(\frac{K_{\mathrm{Ic}}}{\sigma_{0}}\right)^{2}=\frac{G_{\mathrm{Ic}}}{\sigma_{0}^{2}} E
$$




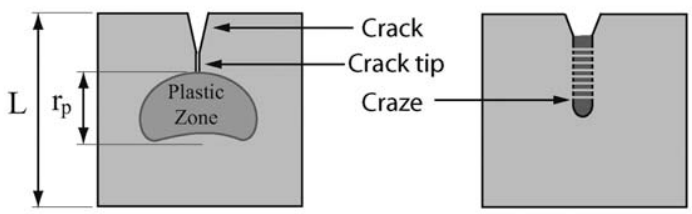

(B)

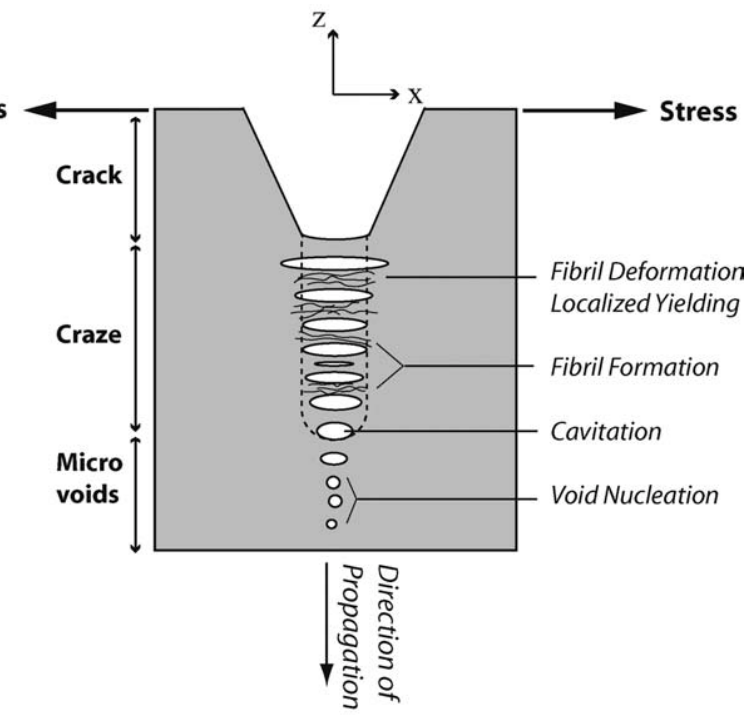

(C)

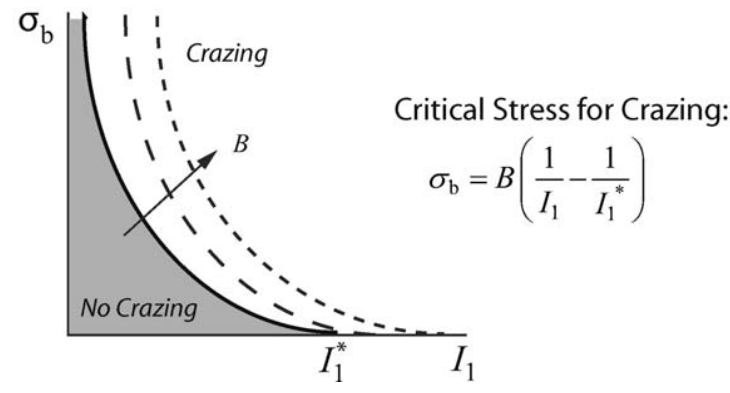

FIGURE 2 Schematic (A) comparison of a crack and a craze; (B) illustration of craze formation and growth with fibrillation, void formation, and nucleation; (C) stress-bias criterion showing the stress states required for crazing.

here $\sigma_{0}$ is the yield strength, $E$ is Young's modulus, $K_{\text {Ic }}$ is the fracture toughness, and $G_{\text {Ic }}$ is the critical energy release rate (fracture energy). ${ }^{44,45}$ Variations in yield strength, Young's modulus, and fracture energy of a Nafion ${ }^{\circledR}$ membrane due to temperature and/or humidity changes are in the range of 2-15 MPa, 50-250 MPa (from Tang et al. ${ }^{37,46}$ ), and $250-550 \mathrm{~J} / \mathrm{m}^{2}$ (from Patankar et al. and Li et al. ${ }^{22,35}$ ), respectively, which suggests that the size of the plastic zone is comparable or larger than the thickness range for the most commercial PFSA membranes (20-175 $\mu \mathrm{m})$. Therefore, the concept of small-scale yielding, and consequently LEFM, is not generally applicable for failure of polymer fuel cell membranes. Thus, crack growth mechanisms in polymer fuel cell membranes should be studied within the framework of elastic-plastic deformation (e.g., using the J-integral).

\section{Crazing and Craze Growth}

Crazes in polymers are regions of highly localized deformation, which require the presence of hydrostatic tension. Crazes nucleate in regions with stress concentrations such as crack-tips, pinholes, and surface defects, when the hydrostatic tension is sufficiently large [Fig. 2(B)]. ${ }^{47-49}$ A typical crazed region consists of polymer fibrils with voids in between. Crazing is similar to shear band formation in that they both involve localized yielding and consequently energy dissipation, but crazing occurs only under tension. For thin film polymers, a craze can be described as a localized deformation zone (analogous to a necking zone during ductile yielding) with a superimposed fibril structure. ${ }^{50}$

Crazes are load bearing as their surfaces are bridged by nanometer-sized fibrils [Fig. 2(A,B)]. ${ }^{49}$ Consequently, the fracture toughness of a polymer is affected by the competition between fracture resistance, shear yielding, and crazing. ${ }^{51}$ According to Kramer and Berger, ${ }^{49}$ craze growth mechanisms can be classified into two categories: (i) craze tip advance, which is essentially crack formation, or (ii) craze widening, which corresponds to fibril formation and deformation [Fig. 2(B)]. As the fibrils deform and elongate in the latter case, crazes grow in width and eventually the fibrils break down, resulting in separation of the material behind the crack-tip, similar to crack propagation. ${ }^{49}$ Thus, craze growth can be considered as a precursor to crack propagation.

Even though crazing is common in glassy polymers, void formation and subsequent craze formation can occur in semicrystalline thermoplastics as well. $^{52}$ For example, crack growth in PTFE (which forms the backbone of PFSA membranes) during fatigue ${ }^{53,54}$ and fracture tests ${ }^{55,56}$ shows the existence of fibrillation and void formation. Brown et al. ${ }^{55,56}$ observed the characteristic features of crack propagation in PTFE with two major failure mechanisms: (i) brittle fracture with cleavage and microvoid coalescence at temperatures below $15{ }^{\circ} \mathrm{C}$, and (ii) ductile failure with stable crack growth during which fibrils are formed, at higher temperatures. Fibrils, once nucleated at a point of stress concentration, elongate in the direction of the maximum principal stress with further loading [Fig. 2(B)], leading to localized plastic deformations and slowing the crack propagation by bridging the crack plane. ${ }^{56}$ When the fibrils in the polymer network are strong enough (even temporarily) to hold the crack, craze formation occurs. ${ }^{48}$ Temperature also has an important role in the mechanisms governing this type of failure. For example, increasing the temperature might lead to a brittleto-ductile transition, which promotes, shear deformation in favor of crazing for some materials including PTFE, ${ }^{55,56}$ even though the opposite effect has also been reported for some other polymers. ${ }^{49}$

\section{CRAZING CRITERION}

This section discusses the theory of a crazing criterion and its adoption to investigate the failure in fuel cell membranes during RH cycling using numerical simulations. 


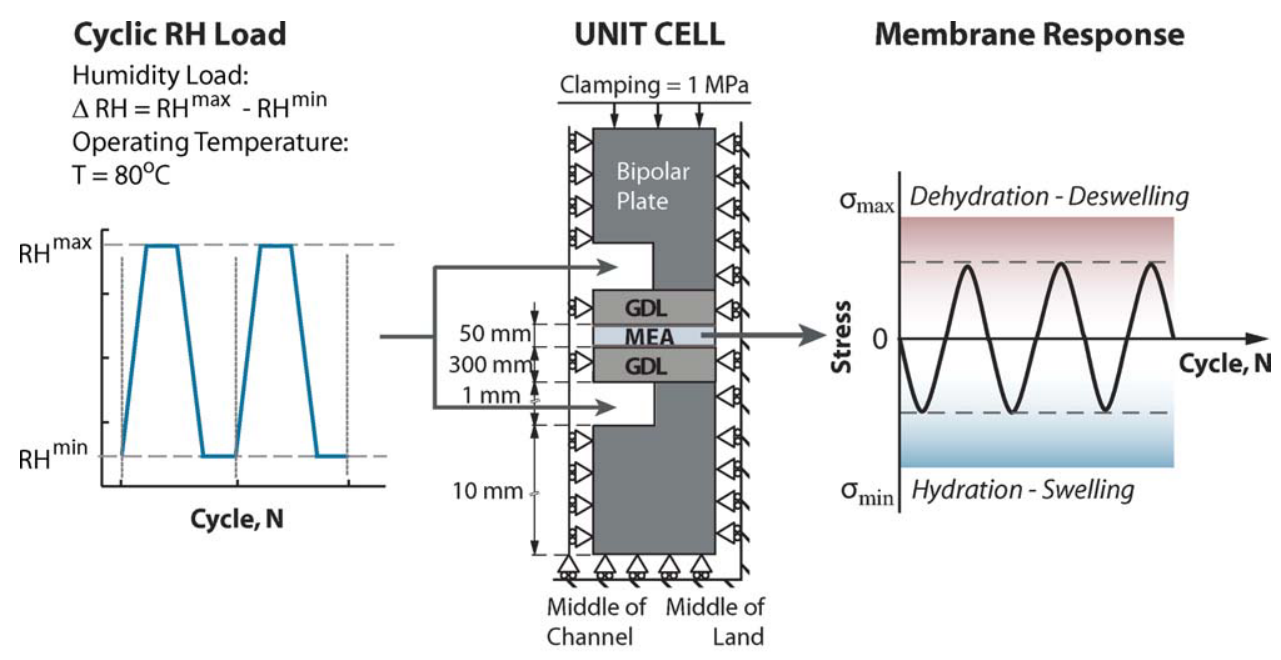

Stress-State in the Membrane (MEA)

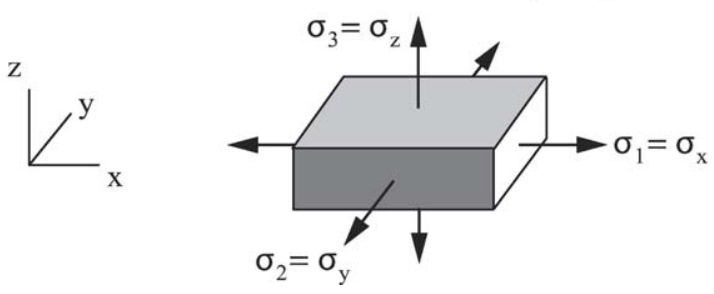

FIGURE 3 Overview of the numerical modeling frame with a representative sketch of mechanical response of the membrane due to $\mathrm{RH}$ cycle test input and geometric cell constraints (note: the unit cell is not to scale). The stress state in the membrane indicates the sign and notation convention used.

Sternstein and Ongchin ${ }^{57}$ introduced a criterion for crazing in polymers based on the "normal stress yielding criterion" and the hydrostatic stress state. The stress required for crazing is determined by the competition between stress bias, $\sigma_{\mathrm{b}}$, responsible for the orientation of crazes by means of yielding and the hydrostatic tensile stress necessary for the cavitation process. ${ }^{57}$ Hydrostatic stress is given by $p=I_{1} / 3$, where $I_{1}$ is the first stress invariant, $I_{1}=\sigma_{1}^{\mathrm{p}}+\sigma_{2}^{\mathrm{p}}+\sigma_{3}^{\mathrm{p}}$, and $\sigma_{1}^{\mathrm{p}}, \sigma_{2}^{\mathrm{p}}$, and $\sigma_{3}^{\mathrm{p}}$ are the principal stresses. (Principal stresses are the eigenvalues of the stress tensor. Physically, this can be interpreted as the normal stresses obtained when the coordinate system is selected so that all shear stresses vanish for a given state of stress.) Sternstein and Ongchin defined the critical stress bias required for crazing as the superposition of principal stress for yielding and hydrostatic stress for cavitation ${ }^{57,58}$ [Fig. 2(C)]:

$$
\sigma_{\mathrm{b}}=\left|\sigma_{1}^{\mathrm{p}}-\sigma_{3}^{\mathrm{p}}\right|=\frac{B(T, \mathrm{RH})}{I_{1}}-A(T, \mathrm{RH}), \quad\left(I_{1}>0\right),
$$

where the stress bias is in the direction of $\max \left(\sigma_{1}^{\mathrm{p}}, \sigma_{3}^{\mathrm{p}}\right)$ with $\sigma_{1}^{\mathrm{p}}$ and $\sigma_{3}^{\mathrm{p}}$ being the major and minor principal stresses, and $A$ and $B$ are temperature- and humidity-dependent material constants. The left-hand side of eq 2 corresponds to the yield criteria according to Tresca ${ }^{59}$ for the bulk material.

The first term on the right-hand side derives from considerations of polymer chain mobility, and it follows that the stress bias required for the orientation process should decrease as the hydrostatic tensile stress increases. This is in accord with the observation of the absence of crazing under pure shear or compression. ${ }^{57,58}$ Under purely hydrostatic tension (i.e., $\sigma_{1}^{\mathrm{p}}=\sigma_{2}^{\mathrm{p}}=\sigma_{3}^{\mathrm{p}}$ ) the stress bias vanishes, and from eq 2 the critical first stress invariant, $I_{1}^{*}=B / A$ is obtained, which represents the critical hydrostatic tensile stress state at which any small deviation in stress will trigger orientation and crazing. In this case, the stress bias can be written as

$$
\sigma_{b}=B \frac{1}{I_{1}}-\frac{1}{I_{1}^{*}} \quad 0<I_{1}<I_{1}^{*} .
$$

Moreover, the material constant $A$ can be assumed proportional to the yield strength, that is, $A=\alpha \sigma_{\mathrm{y}}{ }^{51}$ where $\alpha$ is a constant of proportionality and $\sigma_{\mathrm{y}}$ the yield strength. It follows that $B=I_{1}^{*} A=I_{1}^{*} \alpha \sigma_{\mathrm{y}}$, and thus $B$ characterizes the onset of crazing based on yielding and the hydrostatic stress. This shows that ductile yielding is critical for crazing.

Despite its limitations as discussed in Bucknall, ${ }^{48}$ the stressbias criterion (or its modified versions) has been shown to predict the experimentally observed crazing conditions in a variety of materials. ${ }^{48,57,58,60,61}$ For example, when the stress bias for PMMA was plotted as a function of $I_{1}$, an empirical relationship in the form of eq 3 was obtained. ${ }^{57,58}$ Also, for polystyrene films, there exists a critical minimum strain for crazing to occur, ${ }^{52}$ and the number of crazes was found to increase with increasing strain level. ${ }^{47}$ 
TABLE 1 Mechanical Properties for the Experimental Reinforced PFSA Membrane at Selected Temperatures and Humidities Taken from Tang et al. ${ }^{37,46}$

\begin{tabular}{|c|c|c|c|c|}
\hline \multicolumn{2}{|c|}{ Environmental Conditions } & \multirow{2}{*}{$\begin{array}{l}\text { Elastic Response } \\
\text { Young's Modulus, } \\
E(\mathrm{MPa}) \text { Initial }\end{array}$} & \multicolumn{2}{|c|}{ Plastic Response } \\
\hline $\begin{array}{l}\text { Temperature, } \\
T\left({ }^{\circ} \mathrm{C}\right)\end{array}$ & $\begin{array}{l}\text { Humidity, } \\
\text { RH (\%) }\end{array}$ & & $\begin{array}{l}\text { Yield Strength, } \\
\sigma_{y}\left(\bar{\varepsilon}^{p l}=0\right) \\
\text { Stress at } 0 \\
\text { Plastic Strain }\end{array}$ & $\begin{array}{l}(\mathrm{MPa}) \sigma\left(\bar{\varepsilon}^{p l}=0.3\right) \\
\text { Stress at } 0.3 \\
\text { Plastic Strain }\end{array}$ \\
\hline 25 & 30 & 584.8 & 18.46 & 53.95 \\
\hline 25 & 50 & 532.0 & 15.62 & 47.40 \\
\hline 25 & 90 & 416.3 & 11.01 & 39.00 \\
\hline 85 & 30 & 121.7 & 4.19 & 17.38 \\
\hline 85 & 50 & 111.35 & 4.43 & 19.04 \\
\hline 85 & 90 & 93.9 & 3.12 & 15.08 \\
\hline
\end{tabular}

\section{NUMERICAL MODEL AND RESULTS}

\section{Overview}

Stresses and in-elastic strains are important parameters that characterize the overall deformation behavior of the membrane in a fuel cell assembly and can be used to investigate potential failure mechanisms. Thus, we will use the commercial finite element code ABAQUS to adapt a previously developed numerical model, ${ }^{10}$ which can predict the stresses that evolve in the polymer fuel cell membrane during fuel cell operation. The geometry of the unit cell and the loading conditions used in the simulations are illustrated in Figure 3. Symmetry boundary conditions at the left and right edges of the unit cell are assumed. Further details about the elastoplastic response of the membrane, numerical modeling of the unit fuel cell, and properties of the other cell components are discussed in the articles by Kusoglu et al. ${ }^{9,10,62}$ The temperature- and humidity-dependent experimental data for the stress-strain behavior of the reinforced membrane (The ePTFE-reinforced noncommercial membranes are provided by W.L. Gore \& Associates. Also, we note that the membrane in the simulation is not exactly the same as the membrane used in the tests, though both are reinforced. Thus, the comparisons are primarily qualitative.) are taken from Tang et al. ${ }^{46}$ and incorporated into the numerical model as explained in Kusoglu et al. ${ }^{9,10,62}$ Representative values taken from the data set are listed in Tables 1 and 2 . For a complete list of the properties for the reinforced membrane, see Tang et al. ${ }^{46}$ The reinforced membrane is a $20-\mu \mathrm{m}$ thick, experimental composite membrane of PFSA-based ionomer with microporous expanded PTFE (ePTFE) reinforcement provided by W.L. Gore and Associates.

Elastic-plastic properties are used in the finite element model to investigate the overall response. Any inelastic response (time-dependent plasticity or viscoelastic response) will result in a similar behavior: if the compressive stress supersedes the linear limit, tensile stresses are likely to develop during unloading. Simulation of crack propagation via finite element analysis requires a different treatment and is therefore beyond the scope of this article. Instead, the simulation results (e.g., plastic deformation and stress states) will be used to investigate the likelihood of crazing with the help of simple, yet effective, criterion to determine craze formation.

\section{Load Scheme}

For validation of the numerical model, the numerical results will be directly compared to RH cycle tests conducted by Lai et al. $^{7}$ who used Gore ${ }^{\mathrm{TM}}$ Primea ${ }^{\circledR}$ MEAs based on ePTFE-reinforced membranes. To ensure that failures were driven by mechanical stresses only, no current was drawn from the cell and no hydrogen was used in the experiments. The tests were

TABLE 2 Mechanical Properties for the Nafion ${ }^{\circledR}$ Membrane at Selected Temperatures and Humidities Taken from Tang et al. ${ }^{37,46}$

\begin{tabular}{|c|c|c|c|c|}
\hline \multicolumn{2}{|c|}{ Environmental Conditions } & \multirow{3}{*}{$\begin{array}{l}\text { Elastic Response } \\
\text { Young's } \\
\text { Modulus, } \\
E \text { (MPa) }\end{array}$} & \multicolumn{2}{|c|}{ Plastic Response } \\
\hline & & & Yield & $(\mathrm{MPa}) \sigma\left(\bar{\varepsilon}^{p l}=0.3\right)$ \\
\hline $\begin{array}{l}\text { Temperature, } \\
T\left({ }^{\circ} \mathrm{C}\right)\end{array}$ & $\begin{array}{l}\text { Humidity, } \\
\mathrm{RH}(\%)\end{array}$ & & $\begin{array}{l}\text { Strength, } \\
\sigma_{y}\left(\bar{\varepsilon}^{p l}=0\right)\end{array}$ & $\begin{array}{l}\text { Stress at } 0.3 \\
\text { Plastic Strain }\end{array}$ \\
\hline 25 & 30 & 189.3 & 6.61 & 9.71 \\
\hline 25 & 50 & 158.95 & 6.06 & 9.01 \\
\hline 25 & 90 & 92.2 & 3.65 & 7.42 \\
\hline 85 & 30 & 82.6 & 3.40 & 5.01 \\
\hline 85 & 50 & 64.5 & 3.11 & 4.04 \\
\hline 85 & 90 & 33.6 & 1.87 & 3.25 \\
\hline
\end{tabular}



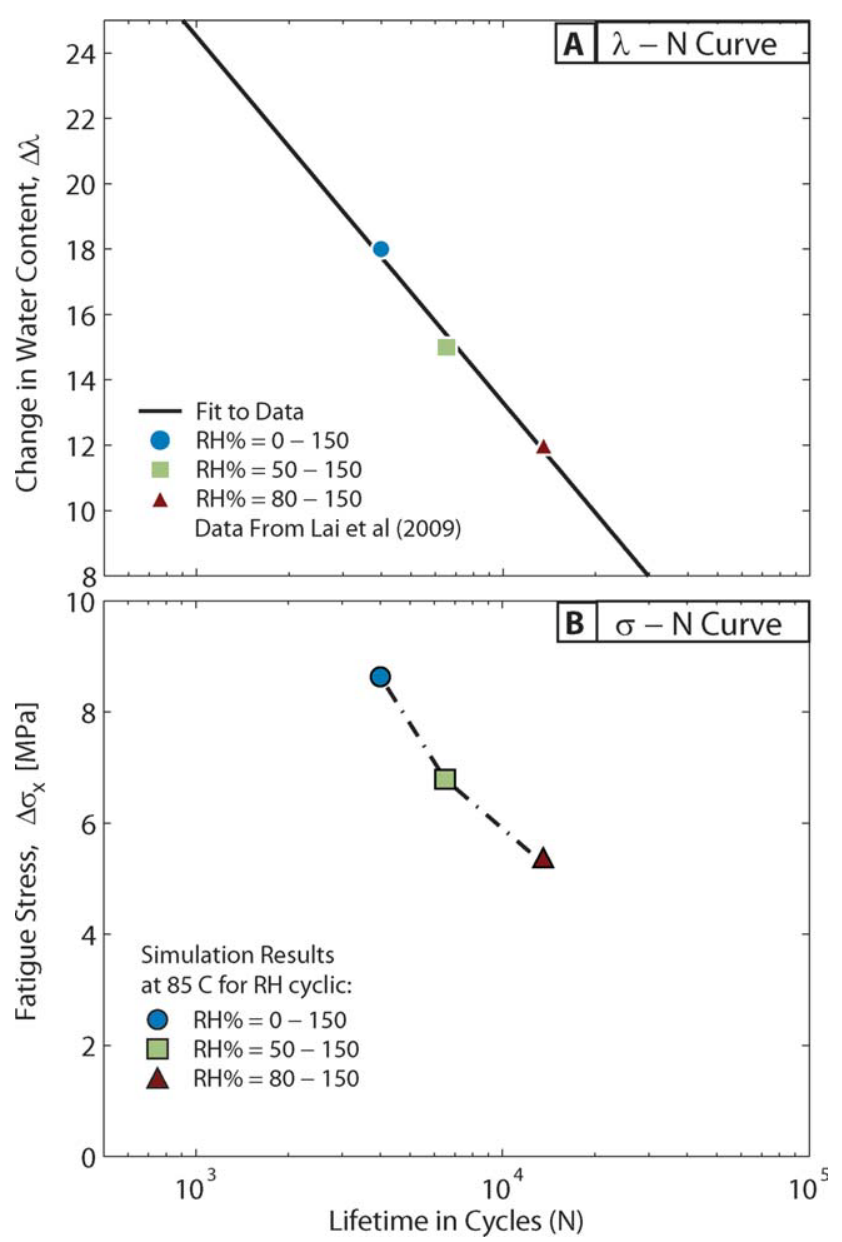

FIGURE 4 Swelling-induced fatigue response of fuel cell membrane: (A) change in the water content, $\Delta \lambda$, versus lifetime, $N$, based on the experimental data from Lai et al., ${ }^{7}$ and (B) corresponding fatigue stress in the plane, $\Delta \sigma_{x}$ (from simulations) for the three $\mathrm{RH}$ amplitudes investigated. Each marker represents a specific test condition in $(A)^{7}$ and corresponding simulation results in (B). Therefore, stress here represents the cyclic steady-state stress.

conducted at a fixed maximum $\mathrm{RH}$ of $150 \%$ (oversaturated condition) with various selected minimum $\mathrm{RH}$ values. The membrane lifetimes for each case are shown in Figure 4(A). ${ }^{7}$ Thus, the RH cycle test loading scheme is implemented into the numerical model, and the evolution of the stresses in the membrane during RH-driven mechanical cycling is determined. A load scheme is adapted from Lai et al. $^{7}$ as follows:

1. Initial condition: The initial condition is defined as $T_{0}=$ $25{ }^{\circ} \mathrm{C}$ and $0 \% \mathrm{RH}$, corresponding to water content in a dry membrane, $\lambda_{0}=2$. These are assumed to be the environmental conditions in which the fuel cells are assembled prior to testing. ${ }^{7}$ The water content is determined from $\mathrm{RH}$ values based on our on-going research and from ref. 14 .

2. Hydrated state: The hydrated state is achieved by increasing the humidity to its maximum value, $\mathrm{RH}^{\max }=150 \%$, corresponding to water content, $\lambda^{\max }=20$ at the cell operating temperature of $80{ }^{\circ} \mathrm{C}$. It this state the membrane is assumed to be liquid-equilibrated and the properties of the membrane were obtained from ref. 32 .

3. Dehydrated state: The dehydrated state is achieved by decreasing the humidity to its minimum value, $\mathrm{RH}^{\mathrm{min}}$, at the cell operating temperature of $80{ }^{\circ} \mathrm{C}$. In this work, three $\mathrm{RH}^{\mathrm{min}}$ values are used: 0,50 , and $80 \%$ corresponding to water contents of $\lambda^{\text {min }}=2,5$, and 8 , respectively. Consequently, the water content (swelling) amplitude, $\Delta \lambda$, is imposed on the membrane based on the $\mathrm{RH}$ amplitude in the cell. Eight hydration-dehydration cycles are simulated, since a cyclic steady stress state is obtained after only a few cycles (Fig. 5).

The water content is imposed at both the anode and cathode flow channels in the numerical model (Fig. 3). Since there is no electrochemical load in the cell, there is no electro-osmotic drag and it suffices to solve the diffusion equations to characterize the water transport in the membrane. Since the same water content at the anode and cathode is assumed, a constant profile through the thickness of membrane is obtained. The diffusion coefficients of water in the

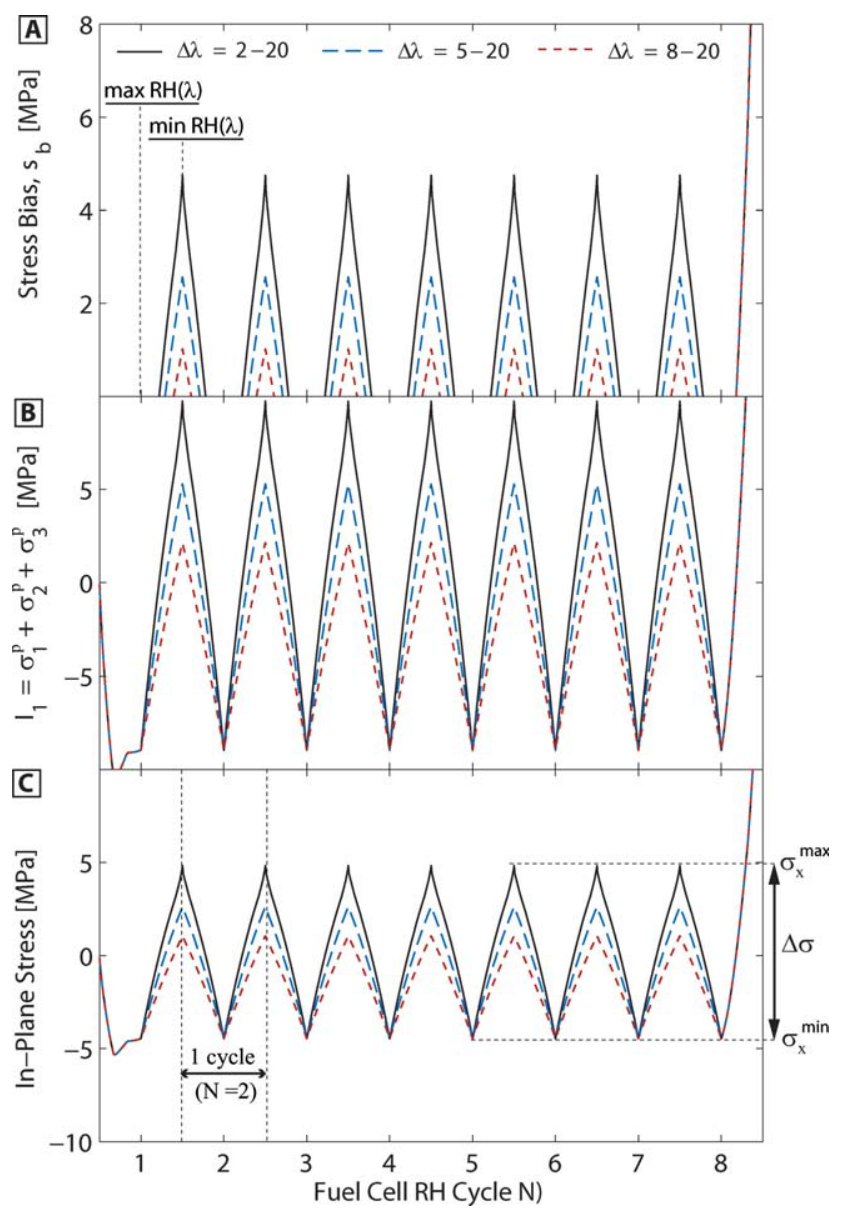

FIGURE 5 Evolution of (A) stress bias from eq 2, (B) first stress invariant, and $(C)$ in-plane stress in the reinforced membrane under the middle-of-channel during fuel cell $\mathrm{RH}$ cycling. 
In-Plane Stress Distribution during Mechanical RH-Cyclic

(A) Maximum Hydration (150\% RH)

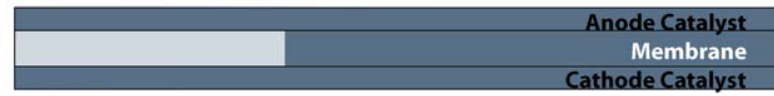

(B) Minimum Hydration case (1) $\mathbf{0} \%$ RH (dry)

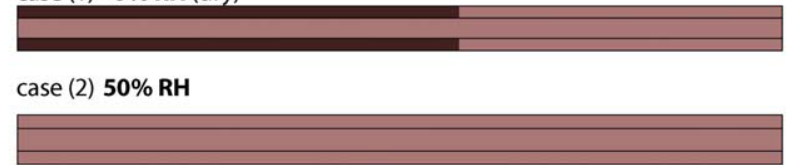

case (3) $\mathbf{8 0} \% \mathbf{R H}$
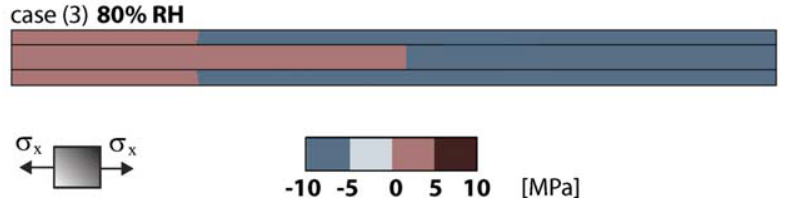

FIGURE 6 Contours of the in-plane stress in the MEAs at (A) maximum hydration ( $150 \% \mathrm{RH})$ and $(\mathrm{B})$ minimum hydration for the three cases investigated of relative humidities: 0,50 , and $80 \%$.

membrane and in the GDL are taken from previous work. ${ }^{10}$ The discussion above pertains to the qualitative behavior. Time-dependent properties may change some of the $\operatorname{details}^{63,64}$ and will affect the quantitative values. However, the overall trends should not be affected.

\section{Mechanical Response}

We will focus the discussion of results on the in-plane component, $\sigma_{\mathrm{x}}$, of the membrane stress since previous work has shown, and this study confirms that this is the dominant stress component in the membrane. ${ }^{9}$ Also, the in-plane stress components are the ones most directly associated with the through-the-thickness cracks, which are of primary concern in the mechanical failure of fuel cell membranes. ${ }^{9,23}$ The overall mechanical response of the MEA is shown in Figure 6 as in-plane stress for the three $\mathrm{RH}$ cycles considered: (i) $0-150 \% \mathrm{RH}$, (ii) $50-150 \% \mathrm{RH}$, and (iii) $80-150 \% \mathrm{RH}$ at the cell operating temperature of $80{ }^{\circ} \mathrm{C}$. The results suggest that stress amplitude, or "fatigue stress," $\Delta \sigma$, in the plane, increases with increasing amplitude of water content, $\Delta \lambda$. Even when considering possible differences in clamping conditions, membrane properties, and cell architecture between the experiments and the simulations, the results depicted in Figures 4-6 reveal a strong correlation between the RH amplitude and fatigue stresses. The correlation between humidity cycling, fatigue stress, and lifetime (as measured in Lai et al. $^{7}$ ) is investigated in Figure 4. Figure 4(A) shows that lifetime (cycles to failure, $N$ ) of the membranes decreases with increasing swelling amplitude, $\Delta \lambda$. According to the simulations, increasing swelling amplitude leads to larger inplane fatigue stresses. The stress-log (cycle) plot depicted in Figure 4(B) exhibits characteristic features of the curves obtained for other polymers, ${ }^{61}$ showing an increasing lifetime directly correlated with a decreasing stress. Pursuing this similarity, we will next investigate the applicability of existing failure theories for polymeric materials to the failure of polymer fuel cell membranes.

Figure 5 depicts the evolution of the in-plane stress, first stress invariant and stress bias, $\sigma_{\mathrm{b}}$, (eq 2) under the midchannel during numerical RH cycle test for eight cycles $(N=$ 8). As mentioned before, a cyclic steady state is reached after the first few cycles: In-plane stresses alternate between compressive and tensile stress, indicating a risk of fatigue [Fig. 5(C)]. The first invariant follows a similar trend [Fig. 5(A)] being negative at high humidity due to the compressive stress state $\left(I_{1}<0\right)$ and becoming positive $\left(I_{1}>0\right)$ at low humidity due to residual tension. Thus, cavitation may develop after dehydration, when the stresses are tensile. Similarly, the evolution of the stress bias suggests that the probability of craze formation is higher during dehydration (i.e., when the humidity is low during cycling). Higher probability of crazing means that damage will more likely occur, even though the accumulation of damage is also controlled by the material properties related to the fracture resistance and environmental factors as will be discussed later.

During the load sequence, the in-plane membrane stresses equal each other $\left(\sigma_{1}=\sigma_{2}\right)$ and the shear stresses are vanishingly small. Thus, the in-plane stresses are approximately equal to the principal stresses, and it follows that the stress bias in eq 2 becomes essentially equal to the effective stress according to the von Mises criterion. ${ }^{65}$ In other words, for this particular case, the stress bias becomes the critical stress that establishes the onset of plastic deformation of the membrane: when the stress bias is equal to the yield strength of the material, yielding will start for the membrane. However, yielding alone is not sufficient to cause crazing. The first invariant, $I_{1}$, must be positive in order for crazing to occur, ${ }^{58,61}$ corresponding to the requirement of a hydrostatic tensile stress state.

\section{Probable Locations and Timing of Crazing and Fatigue Crack Growth}

For simplicity, let us first assume a high value for the critical first stress invariant such that $1 / I_{1}^{*} \rightarrow 0$. Then, eq 2 reduces to $\sigma_{\mathrm{b}} I_{1}=B$. This simplified form might alter the quantitative values for the stresses, but the qualitative trends for the material behavior presented in the following should still be applicable. Estevez et al. showed that when a critical stress state is reached (which is at least half of the yield strength), the craze formation can be directly correlated with the stress level, regardless of the craze initiation mechanism and time $^{51}$ Thus, steady-state stresses might be adequate to investigate the crazing in polymer fuel cell membranes. Even though the crazing is governed only by the state of stress (i.e., the load) and the critical stress (i.e., the material property), both the state of stress and the critical stress may change with time-dependent deformation, temperature, and humidity. In addition, any chemical degradation or other user-time-driven events may alter the critical stress.

The distribution of the first invariant, $I_{1}$, stress bias, $\sigma_{b}$, and $\sigma_{\mathrm{b}} I_{1}$ along the dehydrated membrane taken from middle of 


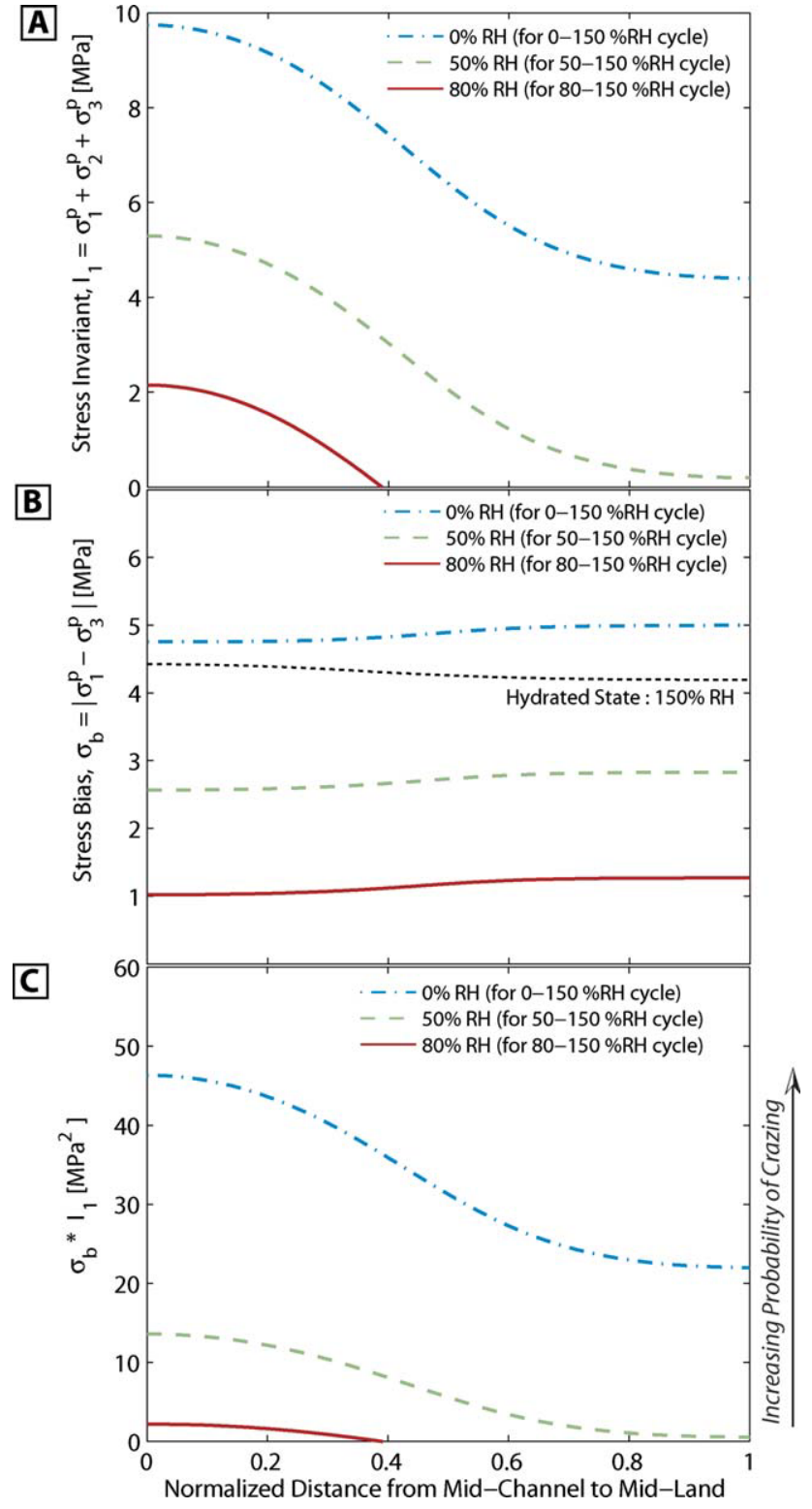

FIGURE 7 Distribution of $(A)$ the first invariant, $l_{1},(B)$ the stress bias, $\sigma_{\mathrm{b}}$, and $(\mathrm{C})$ the products of these terms, $l_{1} \sigma_{\mathrm{b}}$, representing the probability of crazing, plotted from the middle of the channel to the middle of land for three RH cycles investigated.

the channel to the middle of land is depicted in Figure 7(AC). As can be seen from the graph, $I_{1}$ increases at all locations with increasing humidity amplitude (or decreasing dehydration humidity). It attains its highest values under the middle of channels for all cases. Similarly, $\sigma_{b}$ increases with decreasing minimum RH but does not vary much with location. However, even though the $\mathrm{RH}$ has a significant effect on the stress bias, stress bias alone is not sufficient to determine the possibility of failure, since high values are seen in the hydrated state $(150 \% \mathrm{RH})$ as well [Fig. $7(\mathrm{~B})]$. Thus, stress bias must be studied in conjunction with the first invariant to check the possibility of cavitation. Figure $7(\mathrm{C})$ shows that $\sigma_{\mathrm{b}} I_{1}$ follows a similar trend to that observed for first invariant $\left(I_{1}\right)$, with high values reached in the middle of channel and at high humidity amplitudes (Fig. 7). As we do not have any information on the material constant $B$, we cannot check if the criterion $\sigma_{\mathrm{b}} I_{1}=B$ holds for the onset of crazing. However, since all the results are shown at fixed temperature after hydration, a constant $B$ can be assumed, indicating that crazing is more likely to occur for high $\sigma_{\mathrm{b}} I_{1}$ values. For example, if $\sigma_{\mathrm{b}} I_{1}=B$ holds only for the case of 0 $150 \%$ RH cycling, then crazes would not form for the other cases with lower humidity amplitudes. A different value for $B$ would shift the limit up or down, but the overall trends would still be the same since what matters here is the qualitative comparison, rather than the particular values.

Figure 8 shows the stress bias as a function of the reciprocal first stress invariant, eq 3, after dehydration for each $\mathrm{RH}$ cycling case. Since the material properties $A$ and $B$ (and therefore $I_{1}^{*}$ ) are unknown, we treat these as parameters in Figure 8 , so to investigate their effect. In the figure, the onset of crazing is defined by a straight line with slope $B$. At the lower limit for crazing, $B$ is set to the square of the yield strength of PFSA membrane, and at the upper limit, $B$ is the square of the yield strength of ePTFE-reinforced PFSA membrane. As the inverse of the critical stress invariant, $1 / I_{\mathrm{cr}}^{*}$, increases from zero, the data points move to the left of the threshold curve in the figure, hence increasing the likelihood of crazing. This also means that if the critical hydrostatic stress to initiate crazing (or cavitation), $I_{\mathrm{cr}}^{*}$, becomes so low that the right-hand side of eq 2 is negligible or even

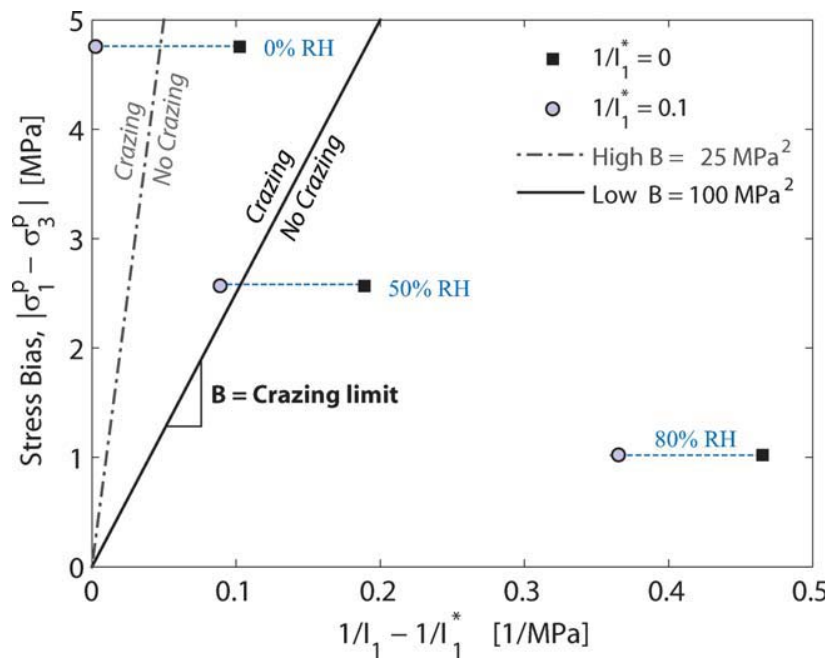

FIGURE 8 Stress bias versus reciprocal first stress invariant (eq 3) for the membrane obtained after dehydration in the middle of the channel. The RH cycling amplitudes are shown next to the data points. The lines represent the critical stress state below which crazes do not form. The slope is the material property, B, for which representative values are chosen arbitrarily. Two cases investigated for the critical stress invariant, 1/ $l_{\mathrm{cr}}^{*}: 0$ and 0.1 . The data points shift leftward with decreasing critical first invariant and would be outside of the axes for very low values, in which case the stress-bias criterion is not valid as the crazes form even at very low stresses. 
negative, the cavitation process begins instantly, even at low stresses $\left(I_{\mathrm{cr}}^{*}\right.$ is a material property indicating the crazing resistance of the polymer). Since $I_{\mathrm{cr}}^{*}$ is not known for PFSA membrane, it is not possible to quantitatively determine the exact stress level for the craze initiation at this point. However, the value of the stress bias clearly increases with increasing $\mathrm{RH}$ amplitude (or higher $\Delta \lambda$ ) making the crazing failure more probable.

In all, the results suggest that the likelihood of crazing of the membrane is the lowest under the land where the hydrostatic stress is compressive and very high $\left(I_{1}<0\right)$ and therefore the stress state cannot meet the criterion for crazing (eq 2). However, crazing is more likely under the channels, where the hydrostatic stress is positive in general $\left(I_{1}>0\right)$ or negative with a low magnitude, due to the lower throughthe-thickness compression. Thus, despite the presence of high stresses in the compressed regions under the lands (due to the contact from bipolar plates), hydrostatic compression of the membrane reduces the probability of the crazing there. The results in the figure are shown after dehydration, that is, when the humidity decreases to its minimum value, since the membrane is compressed in the hydrated state and is therefore not likely to craze due to the negative $I_{1}$. We note that these findings are in agreement with the observations from the actual $\mathrm{RH}$ cycle tests reported in the literature., 19,21 Thus, the failure criterion used in conjunction with the stress analysis presented here is capable of predicting the possible failure locations in the membrane in situ.

\section{DISCUSSION}

Based on the experimental observations, it is possible to develop empirical laws that can predict the lifetime of fuel cell membranes as a function of loading conditions (e.g., humidity, water content, and swelling). The lambda-log time plot in Figure 4(A) indicates a typical fatigue behavior for fuel cell membranes. The slope of the line in Figure 4(A) is a material property indicating the fatigue resistance of the polymer. From this figure, an empirical law could easily be developed to correlate lifetime with swelling amplitude for a particular fuel cell membrane. Empirical laws of this form are useful for life prediction analysis and can therefore serve as a preliminary guideline for the design of new cell architectures, for developing new membranes with different swelling response, and for the investigation of durability under various fuel cell operating conditions. For example, the trend (e.g., slope) in Figure 4(A) is a function of the membrane's mechanical properties and therefore will need to be determined independently for other ionomer membranes. The results shown in Figure 4 are obtained at $80{ }^{\circ} \mathrm{C}$. However, results at other temperatures can easily be investigated in a similar manner, and altering the temperature may possibly alter the slope.

The physical meaning of the parameters $A$ and $B$ (see eq 2) becomes rather complicated, especially in real-life applications. In actual fuel cell operation, there is a complicated combination of mechanical and electrochemical loads, which induces both chemical degradation and mechanical damage. For example, decomposition of the membrane, as well as the formation of pinholes due to chemical degradation (e.g., open circuit voltage decay tests), can cause degradation of the mechanical properties.6,24-26 Thus, degradation of the mechanical properties during cycling might increase the chance of crack propagation, hence causing the parameters $A$ and $B$ to become functions of time and making the failure criterion nonlinear and coupled. Also, thresholds for the onset of crazing (e.g., B) have been shown to decrease with increasing temperature and in the presence of water for other polymers ${ }^{57,58}$ and are likely to do so for PFSA as well.

In addition, the fracture energy of the PFSA membranes depends on both temperature and humidity; therefore, the probability of crack propagation in an ex situ test is higher at higher temperatures and humidities. ${ }^{22}$ Therefore, the environmental fatigue behavior of membranes is highly nonlinear and coupled. However, the in situ fatigue behavior may be even more interesting. For example, in a high temperature-high humidity environment, even though the fracture energy is low, ${ }^{22}$ the membrane experiences compressive stress (as shown in this and previous work ${ }^{9,10}$ ), which is not likely to trigger crack propagation, as discussed in the previous section. However, the yield strength of the membrane also decreases at higher temperatures and humidities, which results in a higher accumulation of inelastic (plastic) strain. This, in turn, causes tensile stresses to develop in the membrane upon cooling and/or drying. Therefore, in a dry and cold environment, there is much more energy available for crack propagation, but the energy has to overcome a much higher threshold since the fracture energy increases. (This could be interpreted as an increase in the parameter $B$ in eq 2.) At the same time, chemical degradation must be considered, since a low humidity environment tends to increase the rate of chemical degradation. 6,24,66-69 This could create more flaws and additional local discontinuities (e.g., voids and pinholes), in addition to reducing the break strain and strength of the material. ${ }^{6,25}$ Taken together, this would increase the overall probability of failure. As noted previously, the time-dependent mechanical response of the membrane would need to be incorporated for the development of a quantitative lifetime prediction model.

In all, environmental conditions will have a strong influence on the failure mechanisms, and these mechanisms compete against each other under the range of conditions to which the fuel cell is subjected. A full understanding of these relationships requires a detailed investigation of the subject with more sophisticated models and systematic tests to link the fracture mechanics and in situ hygrothermomechanical response and take account of the effects of chemical degradation.

\section{CONCLUDING REMARKS}

In this work, we have investigated the swelling-driven fatigue behavior of polymer fuel cell membranes during 
mechanical-only $\mathrm{RH}$ cycling. The swelling-induced stresses were determined via numerical simulations of fuel cell $\mathrm{RH}$ cycle tests. The correlation between the lifetimes from actual tests and the simulation results suggest that higher $\mathrm{RH}$ amplitude and therefore higher swelling amplitude leads to larger fatigue stresses (i.e., stress amplitude) and a lower number of cycles to failure. A crazing criterion ${ }^{48,51,57,58,60}$ that requires the presence of hydrostatic tension was adopted along with yielding for crazing to investigate the potential failure mechanisms during the RH cycling. Since hydrostatic tensile stress is critical for forming cavities that may eventually lead to craze formation, cavitation is less likely in membrane in compression at high humidities. Furthermore, the simulations, along with the crazing criterion for polymer fuel cell membranes, suggest that crack/craze initiation during $\mathrm{RH}$ cycling is more likely to occur in the regions under the channels, a conclusion which is in agreement with experimental observations in the literature.

Craze growth is a necessary step for crack advance in polymers, but not a sufficient condition for failure. Deformation and eventual breakdown of craze fibrils, which is related to the strength and structure of the fibrils, is the controlling mechanism. ${ }^{49}$ The structure and properties of the polymer network, together with the environmental conditions, control the rate and characteristics of the failure. Thus, further work is needed to understand the fundamentals of craze initiation and crack propagation during hygrothermal fatigue, especially in a chemically aggressive fuel cell environment. Also, the stress-log time plots for the polymer fuel cell membranes exhibit similar features to that observed for other polymers (under strain-controlled fatigue tests). Therefore, existing theories of the failure mechanisms in polymers might be employed to develop life prediction models for PEMs in fuel cells and to eventually improve the durability of polymer fuel cell membranes.

\section{REFERENCES AND NOTES}

1 Borup, R.; Meyers, J.; Pivovar, B.; Kim, Y. S.; Mukundan, R.; Garland, N.; Myers, D.; Wilson, M.; Garzon, F.; Wood, D.; Zelenay, P.; More, K.; Stroh, K.; Zawodzinski, T.; Boncella, J.; McGrath, J. E.; Inaba, M.; Miyatake, K.; Hori, M.; Ota, K.; Ogumi, Z.; Miyata, S.; Nishikata, A.; Siroma, Z.; Uchimoto, Y.; Yasuda, K.; Kimijima, K. I.; Iwashita, N. Chem. Rev. 2007, 107, 3904-3951.

2 Garland, N. L.; Kopasz, J. P. J. Power Sources 2007, 172, 94-99.

3 Mathias, M. F.; Makharia, R.; Gasteiger, H. A.; Conley, J. J.; Fuller, T. J.; Gittleman, C. J.; Kocha, S. S.; Miller, D. P.; Mittelsteadt, C. K.; Xie, T.; Van, S. G.; Yu, P. T. Electrochem. Soc. Interface 2005, 14, 24-35.

4 Crum, M.; Liu, W. ECS Trans. 2006, 3, 541-550.

5 Zhang, S.; Yuan, X.; Wang, H.; Mérida, W.; Zhu, H.; Shen, J.; Wu, S.; Zhang, J. Int. J. Hydrogen Energy 2009, 34, 388-404.

6 Huang, X.; Solasi, R.; Zou, Y.; Feshler, M.; Reifsnider, K.; Condit, D.; Burlatsky, S.; Madden, T. J. Polym. Sci. Part B: Polym. Phys. 2006, 44, 2346-2357.

7 Lai, Y.-H.; Cortney, K. M.; Craig, S. G.; David, A. D. J. Fuel Cell Sci. Technol. 2009, 6, 021002-13.
8 Kusoglu, A.; Karlsson, A. M.; Santare, M. H.; Cleghorn, S.; Johnson, W. B. J. Power Sources 2006, 161, 987-996.

9 Kusoglu, A.; Karlsson, A. M.; Santare, M. H.; Cleghorn, S.; Johnson, W. B. J. Power Sources 2007, 170, 345-358.

10 Kusoglu, A.; Santare, M. H.; Karlsson, A. M.; Cleghorn, S.; Johnson, W. B. J. Electrochem. Soc. 2010, 157, B705-B713.

11 Bograchev, D.; Gueguen, M.; Grandidier, J. C.; Martemianov, S. J. Power Sources 2008, 180, 393-401.

12 Liu, W.; Ruth, K.; Rusch, G. J. New Mater. Electrochem. Syst. 2001, 4, 227-232.

13 Liu, W.; Crum, M. ECS Trans. 2006, 3, 531-540.

14 Griffith, M.; Schmiedel, T. ECS Meet. Abstr. 2008, 802, 1030-1030.

15 Cleghorn, S.; Kolde, J.; Liu, W. In Handbook of Fuel CellsFundamentals, Technology and Applications; Wolf, V.; Arnold, L.; Hubert, G., Eds.; West Sussex, England: Wiley, 2003; 566-575.

16 Kusoglu, A. PhD. Dissertation University of Delaware 2009.

17 Tang, H. L.; Shen, P. K.; Jiang, S. P.; Fang, W.; Mu, P. J. Power Sources 2007, 170, 85-92.

18 Solasi, R.; Zou, Y.; Huang, X.; Reifsnider, K.; Condit, D. J. Power Sources 2007, 167, 366-377.

19 Stanic, V.; Hoberecht, M. In Electrochemistry Society Conference, Honolulu, HI, 2004; p 1891.

20 Rama, P.; Chen, R.; Andrews, J. Proc. Inst. Mech. Eng. Part A: J. Power Energy 2008, 222, 421-441.

21 Kim, S.; Mench, M. M. J. Power Sources 2007, 174, 206-220.

22 Patankar, K.; Dillard, D. A.; Case, S. W.; Ellis, M. W.; Li, Y. Q.; Lai, Y. H.; Budinski, M. K.; Gittleman, C. S. J. Polym. Sci. Part B: Polym. Phys. 2010, 48, 333-343.

23 Li, Y. Q.; Dillard, D. A.; Case, S. W.; Ellis, M. W.; Lai, Y. H.; Gittleman, C. S.; Miller, D. P. J. Power Sources 2009, 194, 873-879.

24 Chen, C.; Fuller, T. F. Polym. Degrad. Stab. 2009, 94, $1436-1447$.

25 Yoon, W.; Huang, X. Y. J. Electrochem. Soc. 2010, 157, B599-B606.

26 Kundu, S.; Simon, L. C.; Fowler, M. W. Polym. Degrad. Stab. 2008, 93, 214-224.

27 Qiao, J. L.; Saito, M.; Hayamizu, K.; Okada, T. J. Electrochem. Soc. 2006, 153, A967-A974.

28 Yoon, W.; Huang, X. ECS Trans. 2010, 33, 907-911.

29 Hara, M.; Jar, P. Y.; Sauer, J. A. Macromolecules 1988, 21, 3183-3186.

30 Hara, M.; Jar, P.; Sauer, J. A. Macromolecules 1990, 23, 4465-4469.

31 Bellinger, M. A.; Sauer, J. A.; Hara, M. Polymer 1997, 38, 309-315.

32 McDonald, R. C.; Mittelsteadt, C. K.; Thompson, E. L. Fuel Cells 2004, 4, 208-213.

33 Dillard, D. A.; Budinski, M.; Lai, Y.-H.; Gittleman, C. In Proceedings of the 3rd International Conference on Fuel Cell Science, Engineering, and Technology, Ypsilanti, MI, 2005; pp 153-159.

34 Dillard, D. A.; Li, Y. O.; Grohs, J. R.; Case, S. W.; Ellis, M. W.; Lai, Y. H.; Budinski, M. K.; Gittleman, C. S. J. Fuel Cell Sci. Technol. 2009, 6, 031014-8.

35 Li, Y. Q.; Quincy, J. K.; Case, S. W.; Ellis, M. W.; Dillard, D. A.; Lai, Y. H.; Budinski, M. K.; Gittleman, C. S. J. Power Sources 2008, 185, 374-380.

36 Kambour, R. P.; Gruner, C. L.; Romagosa, E. E. J. Polym. Sci. Part B: Polym. Phys. 1973, 11, 1879-1890. 
37 Tang, Y.; Karlsson, A. M.; Santare, M. H.; Gilbert, M.; Cleghorn, S.; Johnson, W. B. Mater. Sci. Eng. A 2006, 425, 297-304.

38 Kusoglu, A.; Tang, Y.; Lugo, M.; Karlsson, A. M.; Santare, M. H.; Cleghorn, S.; Johnson, W. B. J. Power Sources 2010, 195, 483-492.

39 Kusoglu, A.; Tang, Y.; Santare, M. H.; Karlsson, A. M.; Cleghorn, S.; Johnson, W. B. J. Fuel Cell Sci. Technol. 2009, 6, 011012-011018.

40 Gebel, G. Polymer 2000, 41, 5829-5838.

41 Kim, M. H.; Glinka, C. J.; Grot, S. A.; Grot, W. G. Macromolecules 2006, 39, 4775-4787.

42 Aldebert, P.; Dreyfus, B.; Pineri, M. Macromolecules 1986, 19, 2651-2653.

43 Brown, H. R. Macromolecules 1991, 24, 2752-2756.

44 Suresh, S. Fatigue of Materials; Cambridge University Press: New York, 1991.

45 Erdogan, F. J. Appl. Mech. 1983, 50, 992-1002.

46 Tang, Y.; Kusoglu, A.; Karlsson, A. M.; Santare, M. H.; Cleghorn, S.; Johnson, W. B. J. Power Sources 2008, 175, 817-825.

47 Lee, J. Y.; Crosby, A. J. Macromolecules 2005, 38, 9711-9717.

48 Bucknall, C. B. Polymer 2007, 48, 1030-1041.

49 Kramer, E.; Berger, L. n Crazing in Polymers, Vol. 2; Kausch, H., Ed.; Springer: Berlin/Heidelberg, 1990; pp 1-68.

50 Krupenkin, T. N.; Fredrickson, G. H. Macromolecules 1999, 32, 5029-5035.

51 Estevez, R.; Tijssens, M. G. A.; Van der Giessen, E. J. Mech. Phys. Solids 2000, 48, 2585-2617.

52 Kambour, R. P. Ind. Eng. Chem. Prod. Res. Dev. 1972, 11, 140-145.

53 Aglan, H.; Gan, Y.; El-Hadik, M.; Faughnan, P.; Bryan, C J. Mater. Sci. 1999, 34, 83-97.
54 Gan, Y. X.; Aglan, H.; Faughnan, P.; Bryan, C. J. Reinf. Plast. Compos. 2001, 20, 766-785.

55 Brown, E. N.; Rae, P. J.; Orler, E. B.; Gray, G. T.; Dattelbaum, D. M. Mater. Sci. Eng. C Biomim. Supramol. Syst. 2006, 26, 1338-1343.

56 Brown, E. N.; Dattelbaum, D. M. Polymer 2005, 46, 3056-3068.

57 Sternstein, S.; Ongchin, L. Abstr. Pap. Am. Chem. Soc. 1969, 10, 1117-1124.

58 Sternstein, S. S.; Ho, T. C. J. Appl. Phys. 1972, 43, 4370-4383.

59 Hill, R. The Mathematical Theory of Plasticity; Clarendon Press: Oxford, 1950.

60 Bucknall, C. B. J. Polym. Sci. Part B: Polym. Phys. 2007, 45, 1399-1409.

61 Hertzberg, R. W.; Manson, J. A. Fatigue of Engineering Plastics; Academic Press: New York, 1980.

62 Kusoglu, A.; Karlsson, A.; Santare, M.; Cleghorn, S.; Johnson, W. B. ECS Trans. 2008, 16, 551-561.

63 Huang, X. Y.; Solasi, R.; Zou, Y.; Feshler, M.; Reifsnider, K.; Condit, D.; Burlatsky, S.; Madden, T. J. Polym. Sci. Part B: Polym. Phys. 2006, 44, 2346-2357.

64 Satterfield, M. B.; Benziger, J. B. J. Polym. Sci. Part B: Polym. Phys. 2009, 47, 11-24.

65 Malvern, L. E. Introduction to the Mechanics of a Continuous Medium; Prentice-Hall: Englewood Cliffs, NJ, 1969.

66 Healy, J.; Hayden, C.; Xie, T.; Olson, K.; Waldo, R.; Brundage, A.; Gasteiger, H.; Abbott, J. Fuel Cells 2005, 5, 302-308.

67 Sethuraman, V. A.; Weidner, J. W.; Haug, A. T.; Protsailo, L. V. J. Electrochem. Soc. 2008, 155, B119-B124.

68 Protsailo, L. In 2006 DOE Hydrogen Program Review, Arlington, VA, 2006.

69 Endoh, E.; Terazono, S.; Widjaja, H.; Takimoto, Y. Electrochem. Solid State Lett. 2004, 7, A209-A211. 